\title{
The Third Party: Healing Eating Disorders Through a Task Model of Couples Therapy
}

\author{
Frani Pollack \\ University of Pennsylvania, Philadelphia, PA \\ E-mail: franisp@yahoo.com
}

Fran Gerstein

Bryn Mawr College Graduate School of Social Work and Social Research, Bryn Mawr, PA E-mail: fgerstein01@gmail.com

Received: September 3, 2019 Accepted: November 20, 2019 Published: December 18, 2019

doi:10.5296/ijsw.v6i2.16069

URL: https://doi.org/10.5296/ijsw.v6i2.16069

\begin{abstract}
Couples therapy is often overlooked in the treatment of eating disorders yet provides a vital role in healing and recovery. In this article we propose a four-step-task model for couples therapy when the female partner has an eating disorder. This psychodynamic model includes narrative techniques to convey pertinent personal history, attachment work, parts work, and shared communication of emotion. The article describes the composite model and details the four steps.
\end{abstract}

Keywords: Couples therapy, Eating disorders, Attachment, Communication of primary and secondary emotion, Parts work, Negative cycle

\section{Introduction}

Healthy relationships seem to be a protective factor against life stressors (Carlson, McNutt, Choi \& Rose, 2002; Whisman \& Baucom, 2012) and secure attachment is the hallmark of a healthy relationship (Johnson \& Greenberg, 1985). Diamond and Diamond (2000, 2005) demonstrate that depressed teens recover when attachment bonds with their parents are repaired. Ward, Ramsay and Treasure (2000) and Tasca and Balfour (2014) emphasize attachment as a main tenet of eating disorder treatment with adolescents and their families. Gerstein and Pollack (2016) describe a composite model in which adolescents enhance their recovery from eating disorders by improving their relationships with parents.

Several theories address couples work in which one person has an eating disorder. Bulik, 


\section{Macrothink}

International Journal of Social Work

ISSN 2332-7278

2019, Vol. 6, No. 2

Baucom, Kirby, and Pisetsky $(2011,2012)$ recommend a couple-based treatment for anorexia called Uniting Couples (in the treatment of) Anorexia Nervosa (UCAN), which utilizes a problem-solving/CBT orientation. UCAN also integrates treatment of sexual issues, relapse prevention, and communication.

In their work with couples with an eating disorder, Dick, Renes, Morotti and Strange (2013) note that communication, on the part of the woman, is often characterized by avoidance of conflict. They hypothesize that a woman might fear that openness about her eating disorder could lead to the disclosure of other secrets, like childhood abuse. They conclude that eating disorders indicate anxiety about abandonment, mistrust and avoidance of closeness. In their strategies for helping couples they emphasize support of the male partner, as well as inviting him to play a supportive role to the woman.

Although it is not often used in the treatment of adult couples, the Maudsley method is a well-researched family model in working with eating disorders (Treasure, 2009; Lock \& LeGrange, 2013). It has shown great success with eating disorders (primarily anorexia) in the family, demonstrating that parents are the best agents of recovery. However, there may be limits in the Maudsley method's application to couples since a spouse can be supportive around eating disorder behavior, yet his controlling food and eating is usually not conducive to the development of a healthy adult-adult relationship.

\section{Literature Review}

\subsection{Attachment}

Insecure attachment underlies psychological symptoms including depression, anxiety, addiction and eating disorders (Roberts, Gotlib, \& Kassel, 1996). Eating disorders are one (albeit unhealthy) way of dealing with attachment disruption. Bruch (1982) observed this connection, noting that failed attachment leads to unmodulated stress, which can further lead to learned helplessness and post-traumatic stress. A breakdown of attachment creates disconnection, depersonalization, lack of safety, feelings of being out of control, and emptiness (Wallin, 2007). In her work with women with eating disorders, Barth (2008) defines talk therapy as a form of attachment, stating that clients do not reveal themselves until they feel safe in relationship. If, as Barth says, "naming, talking and being understood" (Barth, 2008) are the building blocks of good attachment, then couples can benefit from this, too. Because a woman with an eating disorder may have a history of poor attachment, couples therapy becomes the vehicle for orchestrating a more secure attachment.

According to Johnson (2001) a secure attachment bond is an "active, affectionate, and reciprocal relationship in which couples mutually derive and provide closeness, comfort and security." An attachment rupture occurs when past hurts, betrayals, or miscommunications cause distrust and distance. Repair of these ruptures are essential for increased intimacy and growth.

\subsection{Communication of Emotions}

Emotionally Focused Couples Therapy (EFT), created by Johnson and Greenberg (1985), stresses the importance of the couple speaking honestly and clearly about their concerns and the emotions that accompany them. The goal of EFT (Johnson \& Greenberg, 1985; Johnson, 2004) is to help each person use non-blaming language while uncovering deep feelings so 
that increased mutual compassion and understanding can strengthen the relationship. Often primary feelings (like sadness, fear, and shame) elicit more empathy and understanding from the partner, but are hidden under secondary feelings, such as anger and frustration. Anger and frustration also need to be expressed in direct and healthy ways. The couples therapist becomes the guide in helping them to fully express themselves while affirming and attuning to emotion.

Many theorists have proposed models of clear communication and healthy expression of emotion. Rosenberg's (2015) work on nonviolent communication notes the value of helping people understand their feelings and communicating them, as well as the costs of repression. Imago work for couples by Hendrix (1988) also strongly supports each partner sharing and hearing the other's story.

\subsection{Negative Cycle}

Another key concept of couples work, the negative cycle, was originally called the negative feedback loop (Bateson, Hayley, Madanes). A negative cycle occurs when one partner triggers the other, who, in turn, triggers the first (Johnson, 2004).

When an eating disorder enters the cycle, it forms a third entity, impeding the couple's ability to communicate and attach directly to one another, akin to a child interfering in the couples relationship and forming a triangle (Bowen, 1978). We hypothesize that as the couple becomes more attuned to the destructive cycle and the role the eating disorder plays in it they can shift a destructive cycle into a healthier interaction.

\subsection{Parts Work}

Over the years, several psychological theorists have discussed individuals as having many parts to their psyche (Assigioli, 1961; Ferruci, 1982). Understanding the desires, needs, and protective nature of these parts has been a helpful way to gain greater understanding of the self. Schwartz (1995) has developed these concepts in a more comprehensive and user-friendly way, which he calls Internal Family Systems (IFS). It was initially used as an individual therapy tool but has since been applied to couples work (Green, 2008). According to IFS theory, the personality is divided into subpersonalities, known as parts. Although parts may have been valuable at one time, they are sometimes forced out of their valuable roles by life experiences that reorganize the system in unhealthy ways (Schwartz, 1995). The goal of IFS is for parts to be integrated so that the individual can better access the executive body for all parts in the system, known as the Self. This is accomplished through compassion and understanding for all parts.

Schwartz noted that eating disorder symptoms were often a vehicle for cut off or denied parts to be seen and experienced. The eating disorder part, named ED by Schaefer (2014), might protect a scared part, a hungry part, an angry part, or an abused or traumatized part. Stereotypically, partners of women with eating disorders might have parts that are involved in saving people, distancing, and/or withdrawing.

IFS couples treatment enables partners to become acquainted with the hidden aspects of the other. Once hidden parts are revealed empathy and compassion often ensue, optimally leading to deeper intimacy for the couple. In our composite model, couples work focuses on the ED part of the woman while noting that other parts may also be creating barriers to intimacy by 
either person in the couple.

\section{Tasks in Healing}

Although tasks may be in order, it is common for this to not be linear.

TASK 1-The person with the eating disorder shares her narrative including pertinent early history and understanding of her eating disorder in the context of couples work. It is important she is in individual therapy to further understand herself. If the eating disorder has been kept a secret from her partner, the effect of its revelation can be quite marked. It is important that the woman feel that she can disclose as much as she cares to and create boundaries, when needed. Her partner is guided to listen empathetically to the personal information shared. She must do the same when he divulges his personal information This sharing of narratives allows partners to develop a deeper understanding of themselves and one another, resulting in mutual empathy and compassion and healing of attachment ruptures.

For instance, an anorexic woman's revelation of a history of sexual abuse explained why she often rejected her partner's sexual advances. Although she explored this first in her individual therapy, the couples therapist helped her reveal the details of her five years of abuse at the hands of a neighbor, allowing her partner to feel less frustrated and more sympathetic. The sharing of this painful story, along with her partner's empathic listening, helped the couple to take steps toward more sexual intimacy.

TASK 2-The eating disorder part is named and identified in couples work including how the eating disorder (ED) has been protective, yet also destructive. The goal here is for both people in the partnership to experience the eating disorder as part of the person, rather than as the whole person. Once ED is seen as a part, both parties can begin to understand ED's intentions and protectiveness. This helps the couple deepen the understanding they attained in Task 1. Sometimes the eating disorder protected a traumatized or vulnerable person from further harm at an earlier time.

For example, one woman disclosed that having a harsh, perfectionist, critical mother resulted in her developing poor self-esteem and self-hatred. Bulimia, ED, comforted her by providing rituals and distraction from her self-loathing. By understanding the role ED played, and sharing it with her partner, she realized that she no longer needed ED for protection and that she could seek out his support instead.

Task 3-The therapist explains the negative cycle and how it involves the eating disorder. Understanding how the cycle works -including the role of the ED- helps the couple see the cycle more clearly, catch themselves when it happens, and co-construct a healthier dynamic. A common example is the woman who tries to get her partner's attention, but in doing so is experienced by him as nagging and critical, resulting in his withdrawing and becoming silent, triggering her to become more nagging and critical. When a woman has an eating disorder, the eating disorder often becomes part of the negative cycle. For example, if the same woman is bulimarexic and tries to connect with her partner through nagging, but he withdraws, she may turn to binging/restricting to deal with his rejection. He may then withdraw further due to his frustration and hopelessness about her binging/restricting. Helping couples understand their cycle and the role of ED increases their awareness and helps them turn toward one another in the moment. Clarifying the cycle and stopping it are the goals of this task. 
Task 4-The therapist helps each partner understand and uncover primary and secondary emotions, elucidating their inner emotional worlds therefore creating deeper understanding, vulnerability, and compassion between them. The therapist helps each partner communicate their thoughts and feelings directly, helping them articulate the frustration, hurt, and distance that has developed over time in the relationship. This task includes an enactment in which partners practice new skills in the presence of the couples therapist.

For instance, a woman struggling with binge eating disorder often turned to food to deal with her strong emotions. She had grown up in a family where any expression of emotion was considered bad and meant she was out of control which resulted in her using food to push down unwanted feelings. In couples work, instead of turning to food she was encouraged to state her feelings directly. Upset that her husband was often at work and therefore unavailable, she was supported to say, "I feel angry and frustrated that you're not here and that we don't spend time together." After her anger was understood by him, she was able to access the fear and pain over his neglect.

\section{Clinical Vignette \# 1:}

In the case of Caren and David, Caren initiated treatment, calling to say that she and her fiancé needed therapy because they were in danger of breaking off their engagement. Both Caren and David seemed distant and upset as they entered the office. With some prompting, David revealed that Caren had an eating disorder. Although she told him in the beginning of their relationship that she had some food/body issues, he had not known the extent of her struggle. Her constant obsession with her body and food limited their ability to go out and enjoy dining together. Her body image concerns resulted in a very limited sexual relationship. David feared this pattern would continue and was reluctant to go through with the marriage if Caren did not seek help.

It was evident that Caren's motivation for therapy centered around her fear of losing David, not getting help for herself. Since eating disorders are often ego-syntonic, it is not unusual for one partner to impel the other partner to seek treatment. Caren especially did not want to gain weight. However, she was willing to do both individual and couples work knowing she may have to make some changes to avoid losing David. The therapist continued to see Caren individually in conjunction with seeing her in couple's therapy. In her individual sessions, Caren explored her pain as a child of distant parents and feelings of isolation when she became an overweight child. It was soon understood by her that her poor attachment to her parents affected her ability to attach to others as an adult. The therapist employed CBT to help her manage her exaggerated thoughts and fears over attaining a healthy weight for her body. Reconnecting to friends and art became significant healing factors, as well. Yet, couples work was at the core of her healing. Although Caren had entered treatment out of fear of losing David, it was her ultimately her connection to him that became the primary impetus for change. In other words, individual work alone would have not healed the eating disorder.

During couple sessions, the therapist identified the vicious cycle that often occurred between them. With some probing on the therapist's part, David was able to access the more fearful and hurt feelings underlying his anger. His history involved his parents going through a bad divorce, rendering him fearful of marrying Caren when they were already having problems. Living with his needy, demanding mother, David had felt like a surrogate husband and 
caretaker. He was especially afraid of marrying someone who needed extra care. Through the couple's work, David was able to open up about his past and speak to his fear of the future. He successfully conveyed his sadness about not feeling closer to Caren and how limited their life seemed to be. Because of his ability to speak more deeply and honestly, Caren was able to hear him and feel empathy toward him, instead of feeling isolated from him.

In the following vignette, the therapist uncovers David's fear. This is Task 4: the therapist helps David, who is stuck in anger validate his anger, but also speak to the more vulnerable feelings of aloneness.

Therapist: So, David, when you came home last night and had this nice dinner, but Caren did not eat with you, as usual, what was that like for you?

David: Horrible. I feel mad every day.

Therapist: So, you are angry often around this issue and Caren hears that and you have done a great job expressing it directly in a healthy way. But now I am wondering when you think about sitting with Caren, but not feeling like she's there. I wonder if you feel something else as well...

David: Like what?

Therapist: Well stay with the image: eating with Caren last night, you were in the kitchen and...

David: I am alone...it's very lonely

Therapist: So, in addition to anger. you are feeling very alone at dinner after a hard day's work. You arrive home and are dining by yourself in a way.

David: Yes. I am afraid that will be my life- dining alone... or being alone.

Therapist: What do you mean?

David: Dining without her... she will be so into the eating disorder that she will not be able to live life with me, nor our children, friends, whomever....

Therapist: Uh huh... So you feel very alone at night eating alone, and you are also thinking what the future will bring. Will you always be alone with food and other things as well? Will life with Caren be lonely? I am guessing that brings fear and perhaps some sadness, is that right?

David: Yes, exactly.

Having David express himself to Caren directly with an emotional focus, helps Caren hear him, and feel more compassion and consider change. Now the therapist will help David directly express this to Caren (continuation of Task 4)

Therapist: Can you turn to Caren and tell her this?

David: I guess (turns toward her) I just feel alone and scared about the future when we are at dinner. It is hard for me and does bring up the past...it's really hard. (looking sad again)

Therapist: (to Caren) How is that for you to hear? What is that like for you? Can you tell him?

Caren: Kind of hard to hear, but it makes me feel badly, like it makes me more want to change the eating disorder. I just do not always know how. I do not want you to feel alone, David. 
The next excerpt is from later in the same session and depicts TASK 1, with Caren sharing her history and how she now understands herself (through individual therapy) with David. In the last part of the dialog, Caren begins to hint at the cycle, which is part of TASK 3

Caren: Frani and I spoke about....well in addition to the whole chubby stuff and getting attention when I was thin....you know that my parents never talked...I just learned to close off feelings and hurts and needs really.... I think Ed became a giant distraction from all my feelings and needs and, also a comfort if I was into overeating ... Ed gave me stuff my parents just could not give.

David: But I can give it to you. Why are you cutting off from me?

Caren: It is still scary. Sometimes you do and you are there, but sometimes you get angry or withdraw and then I use my eating disorder to help me through the tension between us.

In the next excerpt the therapist depicts TASK 3, explaining the cycle, including the role of the eating disorder.

Therapist: So, Caren you are touching on the cycle and although we spoke about it before...I want to go over it again as I think it's very helpful and important to understand. I could start anywhere really, but maybe if it begins at dinner, when Caren cannot eat since ED is saying she cannot, and then David, you feel so angry and frustrated and also lonely and scared but you may express anger or you may withdraw, which triggers Caren to feel a lot of anxiety and fear that you do not love her or may leave her. So she clings to ED to get through it even more, which triggers your anger and fear. Each of you has feelings and actions that trigger the other, and it is really this problematic cycle that gets in the way.

This dialogue is from the following session: TASK 2 is demonstrated as Caren discusses her ED part with David.

Caren: The eating disorder- although hard to have- also protected me....it protected me when I was sad and lonely and my parents were so cold. There is also a sad, scared little girl in me that is so afraid to take a chance... which means going out with you or responding to you. Does that make sense?

David: Yes, it does. It's like how alcohol protected my sister from dealing with her rape. It was bad, but it did protect her from the feelings until she dealt with it in therapy.

Therapist: Yes, David, that is very similar.

David: Okay, so I understand it is protective, but why didn't you tell me about the eating disorder earlier? I just cannot seem to let this go. When we started dating she told me she had some issues, but not this. One year after being engaged I find it out she lied to me.

Therapist: This is very hard... you trusted her and it sounds like your trust has been broken as she did not tell you the entire truth about this. Is that right?

David: Yes, right. She only told me some of it. I do not know if I can trust her. I mean, you have a serious problem that affects us now and may affect us and our family in the future. Like yes, it affects my trust, is there anything else I do not know?

Caren: No, everything else you know. It's just this.

TASK 4 continues as the therapist helps the couple express feelings directly, creating 
another enactment.

Therapist: This is very hard, but Caren, can you tell David why you did not tell him initially?

Caren: Well, honestly, I did not totally know. I thought I had some issues around food but I did not think it was an eating disorder until a few months ago when my doctor told me. But yes, I did not tell you then so .... All I can say is that I am sorry. I am sorry...I am so sorry. I am so scared to lose you. You are the best thing in my life.

David: I hear you. I want this to work, but I do not know. You've got to try to work on this.

Caren: I am. I really am.

David: But the trust... How do I gain trust, again?

Therapist: That will take time. You both just did a nice piece of work being honest and speaking about it. That is a step towards trust. Caren, you need to be honest with David even if he gets upset. Lying or avoiding the truth will only make it worse. And David, I think forgiveness may take time for you but when you see her trying to be honest it will help you to see that she is trying and it will increase your trust.

\section{Conclusion}

Although crucial, couples work is underutilized in the eating disorder field. We propose that four primary tasks are important in helping couples heal. These include the woman with the eating disorder sharing more of her history and narrative, identifying ED and the role it has played, understanding the core negative cycle and the role the eating disorder plays in it, and communicating primary and secondary emotions in clear and direct ways.

Although the Maudsley method (Lock \& LaGrange 2013) has shown good results with adolescents, it is less applicable for adults since an eating disorder can be ego-syntonic, making change difficult and complicated (Kirby, Fischer, Raney, Baucom, \& Bulik 2016). Although UCAN (a CBT-model) has proven to be effective, it is primarily used with anorexia and does not include a psychodynamic frame. The authors feel a psychodynamic attachment model addresses issues in a deeper way, healing the powerful attachment bond that has often been ruptured.

We propose that the best way to heal ruptured attachment is by helping each partner understand the eating disorder through a shared narrative of how it came about and why. Partners support each other when they have more compassion for each other's hidden parts and when they band together to address negative cycles. This helps them bond directly rather than triangulate (with the ED forming a third party).

As we use this model clinically we find ourselves cycling back through these tasks as therapy progresses. For us, the tasks are not linear, but rather progress in an appropriate sequence based on each individual couple. Future research should examine whether a sequence of tasks is more effective at bringing about change. We do emphasize that adequate time and understanding of each task is essential. Although different aspects of this model have been well researched (Papp, 1976; Bruch, 1982; Schwartz, 1995; Klerman \& Weissman, 2001; Johnson, 2004; Diamond, 2005; Hendrix, 2007), research on the effectiveness of this specific combination model has not yet been performed. 
Eating disorders continue to be a devastating disorder with anorexia having the highest death rate of any psychiatric disorder. Despite the increase in research-based treatment models that have been significant in healing this disorder, the significance of couples work should not be underestimated.

\section{References}

Assagioli, R. (1961). Self-realization and psychological disturbances. New York: Psychosynthesis Research Foundation.

Barth, F. D. (2008). Hidden eating disorders: Attachment and affect regulation in the therapeutic relationship. Clinical Social Work Journal, 36(4), 355-365. https://doi.org/10.1007/s10615-008-0164-2

Bowlby, J. (2008). A secure base: Parent-child attachment and healthy human development. Basic books.

Bowen, M. (1978). Family treatment in clinical practice. New York: Jason Aronson.

Bulik, C. M., Baucom, D. H., Kirby, J. S., \& Pisetsky, E. (2011). Uniting couples (in the treatment of) anorexia nervosa (UCAN). International Journal of Eating Disorders, 44(1), 19-28. https://doi.org/10.1002/eat.20790

Bulik, C. M., Baucom, D. H., \& Kirby, J. S. (2012). Couples therapy for anorexia nervosa. A collaborative approach to eating disorders, 189-200.

Bruch, H. (1982). Anorexia nervosa: Therapy and theory. American journal of Psychiatry, 139(12), 1531-1538. https://doi.org/10.1176/ajp.139.12.1531

Carlson, B. E., McNutt, L. A., Choi, D. Y., \& Rose, I. M. (2002). Intimate partner abuse and mental health: The role of social support and other protective factors. Violence against women, 8(6), 720-745. https://doi.org/10.1177/10778010222183251

Diamond, G. M., Diamond, G. S., \& Liddle, H. A. (2000). The therapist-parent alliance in family-based therapy for adolescents. Journal of Clinical Psychology, 56(8), 1037-1050. https://doi.org/10.1002/1097-4679(200008)56:8\%3C1037::AID-JCLP4\%3E3.0.CO;2-4

Diamond, G. S. (2005). Attachment-based family therapy for depressed and anxious adolescents. Handbook of clinical family therapy, 17-41.

Dick, C. H., Renes, S. L., Morotti, A., \& Strange, A. T. (2013). Understanding and assisting couples affected by an eating disorder. The American journal of family therapy, 41(3), 232-244. https://doi.org/10.1080/01926187.2012.677728

Ferruci, P. (1982). What we may be: Techniques for psychological and spiritual growth.

Gerstein, F., \& Pollack, F. (2016). Two Case Studies on Family Work with Eating Disorders and Body Image Issues. Clinical Social Work Journal, 44(1), 69-77. https://doi.org/ 10.1007/s10615-015-0566-x

Green, E. J. (2008). Individuals in conflict: An internal family systems approach. The Family Journal, 16(2), 125-131. https://doi.org/10.1177/1066480707313789

Hendrix, H. (1988). Getting the Love Kou Want. Hendrix, H. (2007). Getting the love, you want: A guide for couples. St. Martin's Griffin.

Johnson, S. M., \& Greenberg, L. S. (1985). Emotionally focused couples therapy: An outcome study. Journal of Marital and Family Therapy, 11(3), 313-317. https://doi.org/10.1111/ 
j.1752-0606.1985.tb00624.x

Johnson, S. M., Maddeaux, C., \& Blouin, J. (1998). Emotionally focused family therapy for bulimia: Changing attachment patterns. Psychotherapy: Theory, Research, Practice, Training, 35(2), 238. https://doi.org/10.1037/h0087728

Johnson, S. (2000). Emotionally focused couples therapy. Comparative treatments for relationship dysfunction, 163-185.

Johnson, S. M., Makinen, J. A., \& Millikin, J. W. (2001). Attachment injuries in couple relationships: A new perspective on impasses in couples therapy. Journal of marital and family therapy, 27(2), 145-155. https://doi.org/10.1111/j.1752-0606.2001.tb01152.x

Johnson, S. (2004). The Practice of Emotionally Focused Couple Therapy, Brunner-Routledge, Taylor \& Francis Books.

Johnson, S. M. (2012). The practice of emotionally focused couple therapy: Creating connection. Routledge. https://doi.org/10.4324/9780203843871

Kirby, J. S., Runfola, C. D., Fischer, M. S., Baucom, D. H., \& Bulik, C. M. (2015). Couple-based interventions for adults with eating disorders. Eating disorders, 23(4), 356-365.

Kirby, J. S. Fischer, M. S, Ranev, T. J., Baucom, D. H., \& Builik, C. M. (2016). Couple-based Interventions in the Treatment of Adult Anorexia Nervosa: A Brief Case Example of UCAN. Psychotherapy, 53(2), 241-250. https://doi.org/10.1037/pst0000053

Lock J., LeGrange D., (2013) Treatment Manual for Anorexia Nervosa Second Ed: A family-based approach. Guilford Press, New York.

Papp, P. (1976). Family choreography. Family therapy: Theory and practice, 276-299.

Roberts, J. E., Gotlib, I. H., \& Kassel, J. D. (1996). Adult attachment security and symptoms of depression: The mediating roles of dysfunctional attitudes and low self-esteem. Journal of personality and social psychology, 70(2), 310. https://doi.org/10.1037/0022-3514.70.2.310

Rosenberg, M. (2015). Nonviolent Communication: A Language of Love. Puddle Dance Press.

Shaefer, J. (2014). Life Without Ed: How one Woman Declared Independence from her Eating Disorder and How You can Too. McGraw-Hill.

Schwartz, R. C. (1995). Internal Family Systems Therapy, Guilford Press.

Tasca, G. A., \& Balfour, L. (2014). Attachment and eating disorders: A review of current research. International Journal of Eating Disorders, 47(7), 710-717. https://doi.org/10.1002/ eat. 22302

Treasure, J. (2009). Introduction. In the Clinician's Guide to Collaborative Caring in Eating Disorders (pp. 19-22). Routledge.

Wallin, D. J. (2007). Attachment in psychotherapy. Guilford press.

Ward, A., Ramsay, R., \& Treasure, J. (2000). Attachment research in eating disorders. Psychology and Psychotherapy: Theory, Research and Practice, 73(1), 35-51. https://doi.org/ 10.1348/000711200160282

Whisman, M. A., \& Baucom, D. H. (2012). Intimate relationships and psychopathology. Clinical child and family psychology review, 15(1), 4-13. https://doi.org/10.1007/s10567 $-011-0107-2$ 


\section{Macrothink

\section{Copyright Disclaimer}

Copyright reserved by the author(s).

This article is an open-access article distributed under the terms and conditions of the Creative Commons Attribution license (http://creativecommons.org/licenses/by/3.0/). 